Article

\title{
Fucoxanthin for Topical Administration, a Phototoxic vs. Photoprotective Potential in a Tiered Strategy Assessed by In Vitro Methods
}

\author{
Renata Spagolla Napoleão Tavares ${ }^{1}{ }^{\mathbb{D}}$, Camila Martins Kawakami ${ }^{1}$, Karina de Castro Pereira ${ }^{1}$, \\ Gabriela Timotheo do Amaral ${ }^{1}$, Carolina Gomes Benevenuto ${ }^{1}$, Silvya Stuchi Maria-Engler ${ }^{2}{ }^{(0)}$, \\ Pio Colepicolo ${ }^{3}$, Hosana Maria Debonsi ${ }^{1}$ (I) and Lorena Rigo Gaspar ${ }^{1, *}$ \\ 1 School of Pharmaceutical Sciences of Ribeirão Preto, University of São Paulo, Ribeirão Preto, \\ SP 14040-903 São Paulo, Brazil; renatasnt@usp.br (R.S.N.T.); milakawakami@hotmail.com (C.M.K.); \\ karina.pereira@usp.br (K.d.C.P.); gabriela.timotheo.amaral@usp.br (G.T.d.A.); carolgb@fcfrp.usp.br (C.G.B.); \\ hosana@fcfrp.usp.br (H.M.D.) \\ 2 Clinical and Toxicological Analyses Department, School of Pharmaceutical Sciences, University of São Paulo, \\ SP 05508-000 São Paulo, Brazil; silvya@usp.br \\ 3 Institute of Chemistry, University of São Paulo, SP 05508-000 São Paulo, Brazil; piocolep@iq.usp.br \\ * Correspondence: lorena@fcfrp.usp.br; Tel.: +55 1633154315
}

Received: 18 February 2020; Accepted: 16 March 2020; Published: 17 April 2020

\begin{abstract}
Fucoxanthin possesses a well-described antioxidant activity that might be useful for human skin photoprotection. However, there is a lack of scientific information regarding its properties when applied onto human skin. Thus, the objective of the present study was to assess the photoprotective and phototoxicity potential of fucoxanthin based on its ultraviolet (UVB 280-320 nm; UVA 320-400 nm) and visible (VIS 400-700 nm) absorption, photostability, phototoxicity in 3T3 mouse fibroblast culture vs. full-thickness reconstructed human skin (RHS), and its ability to inhibit reactive oxygen species formation that is induced by UVA on $\mathrm{HaCaT}$ keratinocytes. Later, we evaluated the antioxidant properties of the sunscreen formulation plus $0.5 \%$ fucoxanthin onto RHS to confirm its bioavailability and antioxidant potential through the skin layers. The compound was isolated from the alga Desmarestia anceps. Fucoxanthin, despite presenting chemical photo-instability (dose $6 \mathrm{~J} / \mathrm{cm}^{2}: 35 \%$ UVA and 21\% VIS absorbance reduction), showed acceptable photodegradation (dose $27.5 \mathrm{~J} / \mathrm{cm}^{2}$ : $5.8 \%$ UVB and $12.5 \%$ UVA absorbance reduction) when it was added to a sunscreen at $0.5 \%(w / v)$. In addition, it increased by $72 \%$ of the total sunscreen UV absorption spectra, presenting UV-booster properties. Fucoxanthin presented phototoxic potential in 3 T3 fibroblasts (mean photo effect 0.917), but it was non-phototoxic in the RHS model due to barrier function that was provided by the stratum corneum. In addition, it showed a significant inhibition of ROS formation at $0.01 \%(p<0.001)$, in HaCat, and in a sunscreen at $0.5 \%(w / v)(p<0.001)$, in RHS. In conclusion, in vitro results showed fucoxanthin protective potential to the skin that might contribute to improving the photoprotective potential of sunscreens in vivo.
\end{abstract}

Keywords: antioxidant; fucoxanthin; phototoxicity; photostability; reconstructed human skin

\section{Introduction}

Concerning ultraviolet (UV) damage, at the beginning of this century, not many compounds were available for the protection against UVA $(320-400 \mathrm{~nm})$ radiation and, in response to the growing concern regarding the additional damage that is caused by this radiation, various UVA filters are now available for formulations worldwide. However, the number of UVA filters allowed in the USA is quite limited [1,2]. Another perspective is related to the fact that few compounds offer UVA I (340-400 nm) 
and visible (VIS 400-700 nm) light protection, with increasing evidence of the harmful effects of VIS light on the skin. Liebel and co-workers [3] showed that VIS light induced the generation of high levels of free radicals in humans and of proinflammatory cytokines in vitro.

Even conventional sunscreens containing UVA and UVB filters, active ingredients that absorb or reflect UV, do not entirely block the UV radiation that reaches the skin [4]; additionally, they can undergo photodegradation and produce reactive oxygen species (ROS) with a phototoxic potential [5]. Besides that, some UV filters have controversial data regarding their skin permeation, estrogen-like effects, and induction of cutaneous sensitization and photosensitization [6,7]. They might have harmful impact not only on the human skin, but also on marine life and coral reefs, other aquatic ecosystems, like phytoplankton, marine diatom, and alga growth [8,9]. In 2018, the governor of Hawaii banned the in-state sale of sunscreens containing either oxybenzone or octinoxate, suspected to harm coral reefs [10]. After Hawaii, Florida and Key West followed this trend. This movement has stimulated the urgent research on alternatives and possibly eco-friendly photoprotective compounds [10].

Following this trend, natural and biocompatible UV filters have led to research on carotenoids that could be interesting in the development of new UV filters or UV boosters to increase the protection or performance of sunscreens [11]. Booster is a term that is currently used in the cosmetic field to define substances that, in small amounts, are capable of increasing the effectiveness of some other products [11] (i.e., increasing the effects of UV filters protecting the skin from sunlight-induced ROS production).

Fucoxanthin absorbs from 320 to $500 \mathrm{~nm}$ (UVA I to VIS, $448 \mathrm{~nm}$ max) and its action might avoid UVA-induced photoaging and protect from VIS- induced ROS production [2,12]. Since fucoxanthin contains an alene bond, a conjugated carbonyl group, one 5,6-monoepoxide, and an acetyl group, there is a biological potential that is associated with this structure of the molecule when orally administered [13]. It has been reported that this carotenoid shows intense antioxidant activity, as well as anti-inflammatory, anti-obesity, anti-diabetic, anti-tumor, antihypertensive, and anticancer properties [13,14]. Many authors have suggested the photoprotective effect of fucoxanthin on the skin, including protection against UVB-induced damage when $0.001 \%$ of fucoxanthin is applied to hairless mice [15]. However, its topical properties and safety for the human skin are still unknown.

Alternative in vitro methods validated for preclinical trials are being used to predict the safety and efficacy of unknown natural compounds instead of using animal models to evaluate the potential risk of a test chemical. The use of skin models is physiologically relevant in drug development, since it provides better prediction of human skin safety [16], besides ethical and economic concerns. Thus, for phototoxicity prediction, the recommended in vitro tiered strategy, including monolayer fibroblast 3T3 Neutral Red Uptake Phototoxicity (3T3 NRU PT) and reconstructed human epidermis (RHE), allows for the identification of phototoxic potential without animal testing $[5,17,18]$. Nevertheless, RHE does not present the dermal component, which is essential for many epidermal characteristics and proper skin functionalities, including the improvement of barrier function [19]. In our study, we replaced RHE with reconstructed human skin (RHS) to confirm the ability of the latter to detect the phototoxicity potential. Besides the evaluation of fucoxanthin photosafety, we evaluated the photoprotective potential of this molecule by its photostability under different irradiation exposure and when used in a sunscreen formulation. Additionally, we evaluated the maximal antioxidant potential of this molecule onto immortalized human keratinocytes (HaCat) cells, determining the ideal concentration range that is to be used for this effect. Later, we evaluated the antioxidant properties of the sunscreen formulation plus $0.5 \%$ fucoxanthin onto RHS to confirm its bioavailability and antioxidant potential through the skin layers.

Thus, the objective of the present study was to assess the photoprotective and phototoxicity potential of fucoxanthin based on its UV/VIS absorption, photostability, phototoxicity in 3T3 mouse fibroblast culture vs. full-thickness RHS, and its ability to inhibit reactive oxygen species formation that is induced by UVA on HaCaT keratinocytes. 


\section{Materials and Methods}

\subsection{Alga Material}

During the expedition of 2011 (January 4th, managed by the project PROANTAR (Programa Antártico Brasileiro), the researchers collected 69.00 grams of D. anceps (wet) at the Punta Plaza location-Antarctic Continent (Admiralty Bay 62 $04^{\prime} 14.5^{\prime \prime}-62^{\circ} 10^{\prime} 03.5^{\prime \prime} \mathrm{S}$ and $58^{\circ} 20^{\prime} 15^{\prime \prime}-58^{\circ} 27^{\prime} 60^{\prime \prime}$ $\mathrm{W})$. The material was frozen until the time for transportation to our laboratories in Brazil, at the Laboratory of Organic Chemistry of the Marine Environment-Support Center for Research in Natural and Synthetic Products, School of Pharmaceutical Sciences of Ribeirão Preto (LQOAM-NPPNS, FCFRP-USP). The investigators preserved a sample of the material that was collected in a solution of formaldehyde with $4 \%$ seawater for morphological studies and the preparation of vouchers. They identified the macroalgae according to the standard taxonomic methodology in the Phycology Session and deposited exsiccates in the Phycological Herbarium of the Botanical Institute of São Paulo (SP), Brazil.

\subsection{Extraction and Fractionation}

We used a mass of $69.00 \mathrm{~g}$ (wet weight) to obtain the extract. The material was freshly thawed and washed with distilled water under a vacuum filter. Subsequently, it was fragmented and then extracted with the organic solvent dichloromethane $\left(\mathrm{CH}_{2} \mathrm{Cl}_{2}\right)$ : methanol $(\mathrm{MeOH})(2: 1)$ for 30 min. under stirring, in a thermal blanket with controlled temperature (not exceeding $30{ }^{\circ} \mathrm{C}$ ). The material was filtered and extracted two more times while using ultrasound equipment for 15 minutes in the third procedure. We concentrated the organic D. anceps extract in a rotary evaporator under low pressure (Büchi R-300, Buchi Labotechnik, Flawil, Switzerland) and subjected it to a classical chromatographic column-30 cm with stationary phase Silica Gel 40-63 $\mu \mathrm{m} /$ ASTM Macherey-Nagel (Merck, Darmstadt, Germany), with a polarity gradient using n-hexane, ethyl acetate (EtOAc), and methanol (MeOH) (JT Baker, Port of Spain, Trinidad Y Tobago) to fractionate the extract.

\subsection{Carotenoid Isolation}

For the identification of fucoxanthin, the highest colored mass fractions were subjected to Electrospray Ionization Mass Spectrometry (ESI-MS) techniques (amaZon SL, Bruker, Bil-lerica, MA, USA). To isolate the carotenoid, we employed high-performance liquid chromatography (HPLC), analytical, and semi-preparative analyses while using two different types of equipment with three different columns. The first instrument and column used to yield the sub-purified fractions was a Shimadzu Chromatograph Model SCL-10AVP that was equipped with a Shimadzu diode array UV-VIS detector DAD (SPD-M10 AVP, Shimadzu, Kyoto, Japan), a computerized integration system Class-VP software 5.02 (Shimadzu, Kyoto, Japan) and the following chromatographic columns: analytical Supelco C-18 $(25 \mathrm{~cm} \times 4.4 \mathrm{~mm}, 5 \mu \mathrm{m})$ and semi-preparative LC-18 Supelco $(25 \mathrm{~cm} \times 10 \mathrm{~mm}, 5 \mu \mathrm{m})$. The second analytical column was Polar RP column (100 mm $\times 3 \mathrm{~mm}, 5 \mu \mathrm{m})$ that was used to define a method to purify the carotenoid (from chlorophyll "a" as a contaminant). The second instrument was Shimadzu chromatograph (Shimadzu, Kyoto, Japan), Prominence model, CBM-20th controller, SPD-20th detector UV/VIS, with two pumps (LC-6AD), an FCR-10th automatic collector DGU-20A5 degasser and LC-Solution Single Software, a semi-preparative column Synergi Polar-RP $(250 \mathrm{~mm} \times 10 \mathrm{~mm}, 4 \mathrm{~mm})$, and a semi-preparative Polar-RP guard column $(10 \times 10 \mathrm{~mm}, 4 \mathrm{~mm})$, both being from Phenomenex ${ }^{\circledR}$ (Torrance, CA, USA). 


\subsection{Stability}

\subsubsection{UV Absorption}

Solutions of $100 \mu \mathrm{g} / \mathrm{mL}$ of extract (the ideal concentration for maximal absorbance around $1 \mathrm{AU}$ ), fractions, and fucoxanthin alone in isopropanol were analyzed with a spectrophotometer in the 280 to $700 \mathrm{~nm}$ range for the determination of the UV absorption spectra.

\subsubsection{Photostability Studies}

For the determination of photostability, we studied the crude D. anceps extract, the fraction Fr15 containing fucoxanthin, and fucoxanthin that were isolated from this fraction in an isopropanol solution at $100 \mu \mathrm{g} / \mathrm{mL}$ or dissolved in a sunscreen formulation at $0.5 \%(w / v)$. For the photostability studies in an organic solution, $1 \mathrm{~mL}$ of each solution sample was added to glass beakers and then subjected to solvent evaporation until a dried film was obtained. The samples were then submitted or not to UV radiation of $7 \mathrm{~mW} / \mathrm{cm}^{2}$ emitted from a Philips UVA lamp Actinic BL/10 (Eindhoven, Netherlands) measured with a Dr. Hönle radiometer (Planegg, Germany) equipped with a UVA sensor [20-23]. For the D. anceps extract and Fr15, we applied a cumulative dose of $27.5 \mathrm{~J} / \mathrm{cm}^{2}$. That dose is recommended as being similar to $66 \mathrm{~min}$. of exposure to sunlight at midday $\left(6.94 \mathrm{~mW} / \mathrm{cm}^{2}\right)$ on a typical September sunny day in the Ribeirão Preto, Brazil—latitude $21^{\circ} 10^{\prime} 39^{\prime \prime}$ south and longitude $47^{\circ} 48^{\prime} 37^{\prime \prime}$ west $[4,23]$. We applied a cumulative dose of $6 \mathrm{~J} / \mathrm{cm}^{2}$ to determine the photostability of fucoxanthin in isopropanol (the dose recommended for phototoxicity studies and similar to $14 \mathrm{~min}$. of exposure to sunlight at midday in the Ribeirão Preto region). Each beaker subjected to irradiation had a negative control that was sheltered from light. After irradiation, the dried film was resuspended in $1 \mathrm{~mL}$ of solvent, and the absorption spectrum of the solutions in the 280 to $700 \mathrm{~nm}$ range was analyzed. For the photostability study of fucoxanthin in a sunscreen formulation, we prepared the formulation base with a self-emulsifying wax (cetearyl alcohol, cetearyl glucosyde) and a liquid polymer (hydroxyethyl acrylate, sodium acryloyldimethyltaurate copolymer, squalane, and polysorbate 60 ), and, in the presence of the following UV filters: $4 \%$ avobenzone, $6 \%$ octocrylene, $8 \%$ octyl methoxycinnamate, and 3\% octyl triazone, representing formulation "F3" in the Freitas [22] et al. (2015) study. We proceeded as indicated in the cited study to perform the photostability study using a sunscreen, spreading the preparation onto an area of $10 \mathrm{~cm}^{2}$ (approximately $4 \mathrm{mg} / \mathrm{cm}^{2}$ ) of a glass plate and then left to dry for $15 \mathrm{~min}$. before exposure to a UVA dose of $27.5 \mathrm{~J} / \mathrm{cm}^{2}$. We used the area under the curve (AUC), which is the integral of the absorption spectrum of the samples in the UVB $(280-320 \mathrm{~nm})$, UVA $(320-400 \mathrm{~nm})$, and VIS (400-700 $\mathrm{nm}$ ) ranges using the integration function of the MicroCal OriginPro Software (8 SRO, OriginLab Corporation, Northampton, MA, USA) to calculate the photostability [24]. We expressed the results as a percentage of the area of irradiated samples related to the area of non-irradiated samples.

\subsection{Toxicity and Efficacy}

\subsubsection{Phototoxicity Test in 3 T3 Mouse Fibroblast (3T3 NRU PT)}

In this test, fibroblasts of the Balb 3T3 clone A31 that were provided by Banco de Células do Rio de Janeiro, BCRJ code 0047 (Rio de Janeiro, Brazil) cultured on two 96 well microtiter plates were pre-incubated with eight different concentrations of the test chemical $(6.8-100 \mu \mathrm{g} / \mathrm{mL})$ for one hour. We exposed one plate to a UVA irradiation dose of $9 \mathrm{~J} / \mathrm{cm}^{2}$ (SOL-500 sun simulator that was equipped with a metal halide lamp and H1 filter, Dr. Honle AG, Planegg, Germany), while another one was kept in the dark. The determination of cell viability comparing the plates determinates the substance cyto- and phototoxicity [5,25]. Based on the historical data that was produced in our laboratory, we defined this dose as a dose high enough to elicit a phototoxic response in positive controls and as a dose that did not produce interference higher than $20 \%$ in cell viability, as recommended by the Organisation for Economic Co-operation and Development (OECD) [26]. We measured UVA radiation with the same radiometer mentioned before. For concentration-response analysis, we employed the 
Phototox Version 2.0 software, obtained from Zentralstelle zur Erfassung und Bewertung von Ersatzund Ergänzungsmethoden zum Tierversuch (ZeBeT, Berlin, Germany) that calculates the photoirritation factor (PIF) and mean photo effect (MPE). According to the OECD Test Guideline 432, a substance is predicted to be phototoxic if MPE is higher than 0.15 or the PIF is higher than 5. A test substance with an MPE > 0.1 and < 0.15 (PIF > 1 and $<5$ ) is predicted to be "probably phototoxic" [26]. The positive control was norfloxacin purchased from Sigma-Aldrich (St. Louis, MO, USA) [26].

\subsubsection{Reconstructed Human Skin Model (RHS)}

The ethics committees of Human Research Ethics Committee of Faculty of Pharmaceutical Sciences of Ribeirão Preto, São Paulo, Brazil approved the experimental procedures using primary human fibroblasts and keratinocytes from donated foreskins with informed consent from legal representatives and ethics approval conforming to the principles of the Declaration of Helsinki (CAAE $\mathrm{n}^{\circ}:$ 55438216.0.0000.5403). We constructed the dermal equivalent with $3.6 \times 10^{5}$ fibroblasts, $5 \%$ fetal bovine serum (Gibco, Life Technologies, Carlsbad, CA, USA), and rat-tail type I collagen (Corning, Tewksbury, MA, USA) enough to $3 \mathrm{~mL}$ per insert six-well-plate-size (Corning, Tewksbury, MA, USA). After $2 \mathrm{~h}$, we added $2.9 \times 10^{6}$ of the primary human keratinocytes on top of the dermis equivalent using $2 \mathrm{~mL}$ of keratinocyte medium. They were kept submerged for $24 \mathrm{~h}$. Next, the culture was maintained at the air-liquid interface for 12 days to allow for keratinocytes differentiation [27].

\subsubsection{Phototoxicity Test in RHS}

On the 10th day of tissue cultivation, the skin models were exposed to fucoxanthin solubilized in c12-c15 alkyl benzoate $(0.5 \%, v / v)$, which is a vehicle that is commonly used to solubilize lipophilic chemicals in cosmetics [5]. Sterile filter discs $16 \mathrm{~mm}$ in diameter were soaked in $50 \mu \mathrm{L}$ test chemicals (c12-c15 alkyl benzoate) and directly applied to the stratum corneum of the skin models. Ketoprofen at $3 \%$ in alkyl benzoate is phototoxic and it was used as a positive control. Twenty hours after application of the test substances, the skin models were rinsed with phosphate-buffered saline (PBS), dried with a sterile swab, and then transferred to fresh wells with the medium. The skin models were irradiated (sun simulator mentioned before) with $6 \mathrm{~J} / \mathrm{cm}^{2}$, the dose that was recommended by Kandarova and Liebsch [28], as necessary to produce a phototoxic response in the positive controls without damage to the tissue and the one used to pre-validate the test in 1999 by European Centre for the Validation of Alternative Methods (ECVAM) [29]. We measured UVA radiation with the same radiometer mentioned before, while we kept the non-irradiated plates in a dark box.

\subsubsection{Viability Assay}

RHS viability was measured by the end of the experiment of phototoxicity. It was determined by measuring the metabolic activity of the constructs after exposure and post-incubation while using a colorimetric test. The reduction of mitochondrial dehydrogenase activity was assessed via the decreased formazan production following incubation with MTT (3-(4,5-dimethylthiazol-2yl)-2,5-diphenyltetrazolium bromide, Sigma-Aldrich, Cotia, Brazil). The formazan production was measured at $570 \mathrm{~nm}$. We exposed other constructs in every batch to fucoxanthin, but not to MTT, to evaluate the ability of fucoxanthin to stain the constructs under test conditions. The formazan readings were corrected by the fucoxanthin-related optical densities (O.D.) and compared to those of negative control RHS [30]. The data are presented as relative viability according to Equation (1), where "O.D. $a$ " is from tissues treated and "O.D.b" is the mean of untreated tissues.

$$
\text { Relative viability }(\%)=100 \times \text { O.D.b } / \text { mean O.D.b }
$$

\subsubsection{HaCat Antioxidant Activity by Detection of Intracellular ROS Using $\mathrm{DCFH}_{2}-\mathrm{DA}$}

The keratinocytes HaCaT that were provided by Banco de Células do Rio de Janeiro, BCRJ code 0341 (Rio de Janeiro, Brazil) were seeded in two 96-well plates at a density of $1 \times 10^{5}$ cells/well and then 
incubated at $37^{\circ} \mathrm{C}$ in a $5 \% \mathrm{CO}_{2}$ atmosphere for $24 \mathrm{~h}$. Subsequently, cells were treated for one hour with fucoxanthin at $0.1,1,10$, and $100 \mu \mathrm{g} / \mathrm{mL}$ (the same range of concentrations used for 3T3 NRU PT of 6.8-100 $\mu \mathrm{g} / \mathrm{mL}$ ). Next, we incubated the plates with the probe $2^{\prime}, 7^{\prime}$-dichlorodihydrofluorescein diacetate $\left(\mathrm{DCFH}_{2}\right.$-DA) $(10 \mu \mathrm{M})$ in the dark for $30 \mathrm{~min}$. for permeation into the cell. After the period of incubation, we irradiated one plate with $4 \mathrm{~J} / \mathrm{cm}^{2}$ of UVA radiation (sun simulator), while the other one we kept in dark box. Immediately after irradiation, fluorescence intensity was measured with a microplate reader (BioTek Synergy HT, Winooski, VT, USA) at an excitation wavelength of $485 \mathrm{~nm}$ and emission wavelength of $528 \mathrm{~nm}$ [31,32]. We expressed the results as percent fluorescence intensity when compared to the untreated control irradiated, which was considered to be $100 \%$. Norfloxacin $(100 \mu \mathrm{g} / \mathrm{mL})$ and quercetin $(10 \mu \mathrm{g} / \mathrm{mL})$ were used as controls. All of the experiments were carried out in triplicate in three independent experiments. The experimental data was analyzed statistically by analysis of variance (ANOVA), a parametric test, followed by Tukey's test.

\subsubsection{RHS Antioxidant Activity by Detection of Intracellular ROS Using $\mathrm{DCFH}_{2}-\mathrm{DA}$}

The RHS were incubated with the $\mathrm{DCFH}_{2}$-DA probe in PBS $(50 \mu \mathrm{M})$ in the dark for $45 \mathrm{~min}$. After PBS washing, the tissues were treated with sunscreen with fucoxanthin at $0.5 \%$ (as described in 2.3.2 item) and the control was the sunscreen formulation without it, for $1 \mathrm{~h}$. Subsequently, they were subjected to a dose of $10 \mathrm{~J} / \mathrm{cm}^{2}$ of UVA radiation, while control tissues were kept in the dark. Immediately after the irradiation period and PBS washing, the tissues were frozen in liquid nitrogen and $10 \mathrm{~mm}$ cryostat sections were made. The fluorescence intensity was measured while using a Ti-S inverted Microscope (Nikon Instruments Inc., Amsterdan Netherlands), 488 nm, at 100 ms exposition intensity. The images were quantified using Image J software [33,34]. The results were normalized to area/pixels and expressed in a percentage of fluorescence intensity in comparison to the irradiated and non-irradiated untreated controls.

\section{Results}

\subsection{Extraction and Fractionation}

We obtained the dry extract $(1.29 \mathrm{~g})$ from fresh wet alga material $(69.00 \mathrm{~g})$, with a yield of $2.31 \%$. Next, $1.15 \mathrm{~g}$ of the extract was submitted to fractionation in a classical column, which resulted in 40 fractions. We selected fractions that yielded higher weight to have enough mass for all of the following tests; firstly, the selected fractions were screened in terms of their UV spectra.

\subsection{UV Spectra}

D. anceps extract presented absorption in the region of interest for photoprotection (280-400 nm), especially in the UVA and in the visible range (Figure 1a). Concerning brown algae, the typical absorptions in the regions of $400 \mathrm{~nm}$ and $660 \mathrm{~nm}$ (areas of blue and red, respectively) are due to the presence of carotenoids and chlorophylls, especially "chlorophyll a", which is common to all photosynthetic organisms having a maximum absorption at 420 and $660 \mathrm{~nm}$, respectively. Chlorophyll type "a" is predominant in algae due to its central role in the conversion of photochemical energy, while the chlorophyll " $\mathrm{c}$ " efficiently participates in photosynthesis as an accessory pigment (similar to the role of chlorophyll " $b$ " in plants or green algae) [14].

The spectral composition of light is crucial for photoprotection mechanisms and photosynthetic efficiency and, thus, for the pigment content of macroalgae as well. According to Kuczynska et al. [35], different structures of chlorophyll " $c$ " are responsible for its intense absorption in the region of $530 \mathrm{~nm}$; also, a peak in the $680 \mathrm{~nm}$ region (Figure 1a) could be related to "chlorophyll a". Carotenoids, on the other hand, exhibit intense absorption between 400 and 500 nm, after fractionation (Figure 1b), F15, F15a, F2, and F3a showed high UVA I/VIS absorbance. 
(a)

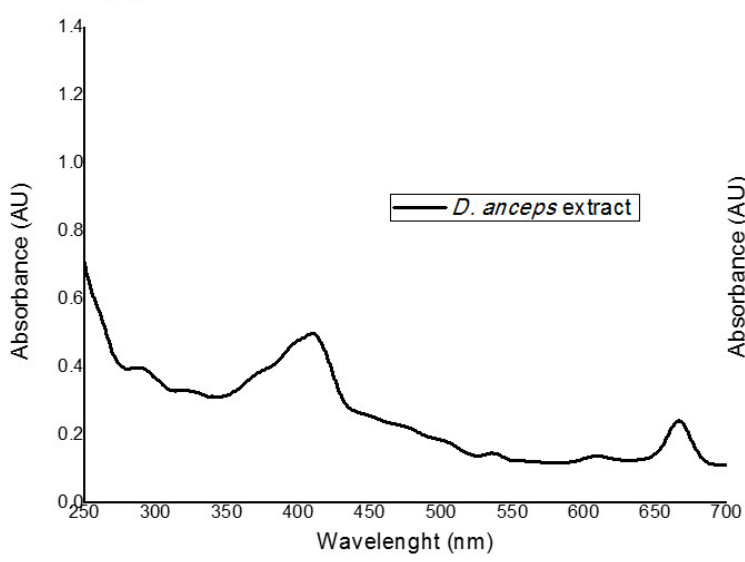

(b)

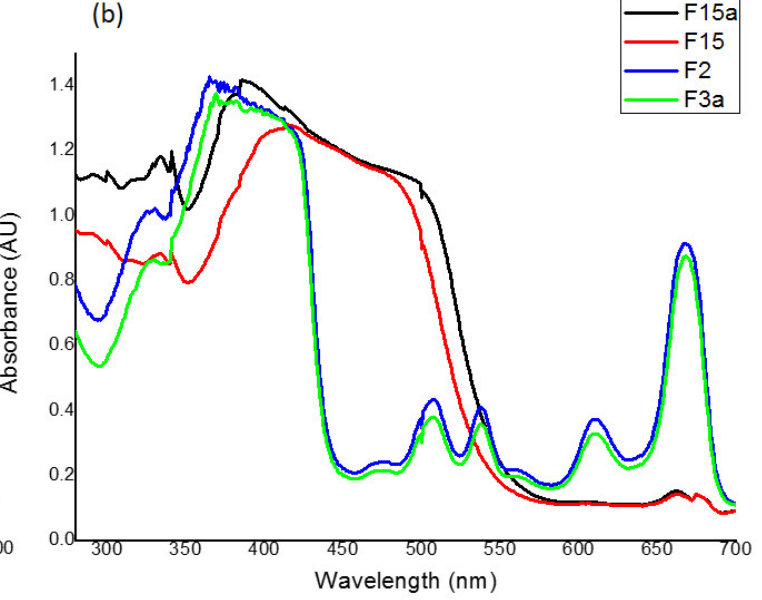

Figure 1. Absorption spectra of (a) The alga D. anceps crude extract; isopropanol solution, $100 \mu \mathrm{g} / \mathrm{mL}$; (b) The fractions obtained from this crude extract presented different spectrum profiles; $F=$ fraction, numbers ordered by elution (nonpolar to polar " $\mathrm{a}$ " indicates the second day of the extraction. Representative curves from triplicates.

\subsection{Identification and Isolation of Fucoxanthin}

The high-resolution molecular mass spectrum (electrospray ionization, ESI) corresponding to the molecular weight of fucoxanthin, $658.90 \mathrm{~g} / \mathrm{mol}$, was identified based on the fragment pattern at $m / z 659.4241$ and 681.3878 corresponding to $[\mathrm{M}+\mathrm{H}]^{+}$and $[\mathrm{M}+\mathrm{Na}]^{+}$in the fractions $\mathrm{F} 15$ and F15a. We subjected the isolated fucoxanthin to NMR spectroscopy for its structural determination while comparing it with the literature (Table 1). The complete assignments of the ${ }^{1} \mathrm{H}$ and ${ }^{13} \mathrm{C} \mathrm{NMR}$ spectra of fucoxanthin revealed signals that were assignable to polyene containing acetyl, conjugated ketone, olefinic methyl, two quaternary germinal oxygen methyls, two quaternaries geminal dimethyl, and allene groups. The NMR data are in line with the findings of Xia and coworkers [14] and Mori and coworkers [36], which suggested that fucoxanthin isolated from the alga D. anceps is mainly present in the all-trans form. By their coloring feature, other pigments, such as any xanthophyll common to brown algae, such as cis-fucoxanthin, diadinoxanthin, diatoxanthine, and $\beta$-carotene, could be present in the alga extract in addition to fucoxanthin [12]. These carotenoids also have a maximum absorption peak around $448 \mathrm{~nm}$, as is the case for chlorophylls (b), (c), and (a), which are the main chlorophyll pigments in algae [14]. For the isolation of fucoxanthin from other carotenoids and chlorophylls, we performed an analytical chromatographic analysis with an exploratory method to verify the presence of compounds that absorb near $450 \mathrm{~nm}$ of fractions F15/F15a (higher yield and absorbance at $448 \mathrm{~nm}$ ). 
Table 1. Nuclear magnetic resonance of hydrogen and carbon $\left(\mathrm{NMR}{ }^{1} \mathrm{H}\right.$ and $\left.{ }^{13} \mathrm{C}\right)$ of fucoxanthin $(500$ and $125 \mathrm{MHz}, \mathrm{CDCl}_{3}$ ) in comparison with literature data (400 and $67.5 \mathrm{MHz}, \mathrm{CDCl}_{3}$ ).

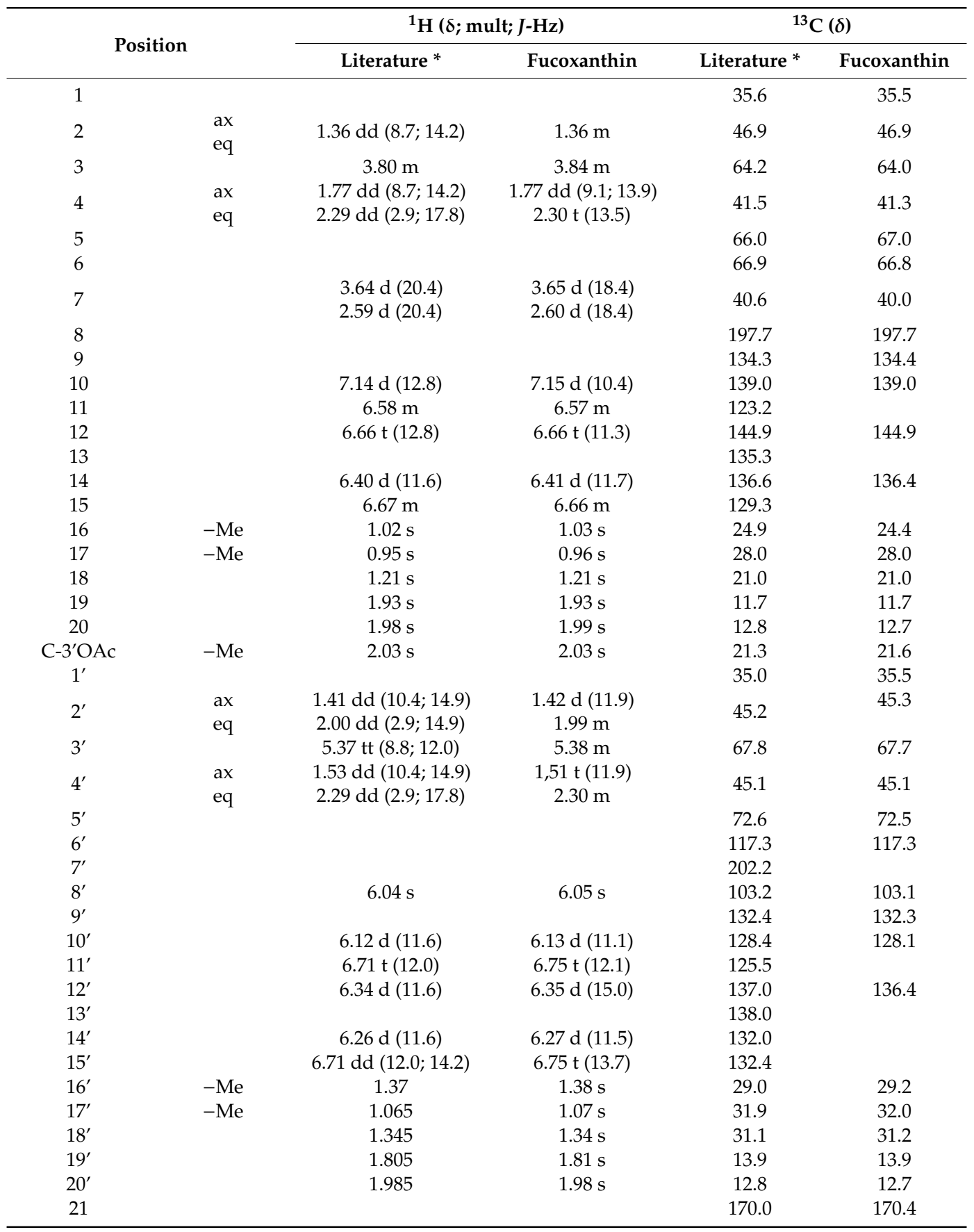

${ }^{*}$ Mori and coworkers, 2004 [36].

We established the method after optimization of analytical chromatographic elution: acetonitrile and water permitted sub-fractionation. The peak with the $47 \mathrm{~min}$. retention time eluted the substance of interest that was monitored by absorption ( $\lambda$ max $\sim 450 \mathrm{~nm}$ ) (Supplementary Figure S1); chlorophyll, (a; c) together with fucoxanthin. Since these algal pigments are complexed, there is greater difficulty in separating them with superior purity [14]. However, after we modified the stationary phase, the mobile phase, and optimized the method employed in analytical chromatographic elution, we could separate them with a rough interval of 3 min (Supplementary Figure S2 or S3). 


\subsection{Photostability Studies}

When irradiated with UVA at $27.5 \mathrm{~J} / \mathrm{cm}^{2}$, the crude extract was considered to be photo unstable in the UV/VIS range (more than 20\% reduction), since there was a $28.5 \%, 43.2 \%$, and $33.7 \%$ decrease in UVB, UVA, and VIS absorption, respectively (Figure 2a, Table 2). Fraction F15 (fucoxanthin rich fraction) with maximal absorbance around $450 \mathrm{~nm}$ was considered to be photostable in UVB, with only a $4 \%$ decrease of absorbance; however, it was photo unstable in the UVA/VIS regions with $44 \%$ and $49 \%$ absorbance depletion, respectively (Figure 2b, Table 2). We then evaluated fucoxanthin that was isolated in isopropanol solution using the same UVA dose used to induce phototoxicity to RHS $\left(6 \mathrm{~J} / \mathrm{cm}^{2}\right)$, in order to compare both of the experiments. With this lower dose, we observed no degradation in the UVB region, 35\% in the UVA region, and 21\% in the VIS region; the depletion of absorption of the isolated compound was not in the range considered to be photostable (Figure 2c) [2,4,37]. We repeated the photostability assay applying $0.5 \%(w / v)$ of pure fucoxanthin in a sunscreen formulation, formulation 3 (F3), based on the photostability studies of Freitas et al. [2]. The final sunscreen formulation was yellow-colored, but it was not able to stain the skin. When we added this marine carotenoid to a sunscreen formulation and irradiated with $27.5 \mathrm{~J} / \mathrm{cm}^{2}$, it was considered photostable $(5.8 \%$ reduction in UVB and 16.5\% reduction in UVA). However, since the sunscreen alone only provoked a reduction in the UVA absorption by $4 \%$, the effect of fucoxanthin on UVA region was considered to be the difference of $12.5 \%$. Additionally, the sunscreen with fucoxanthin increased the general UV absorbance by $72 \%$ compared with the sunscreen alone, proving to act as a UV-booster by light-absorbing effect, Figure $2 \mathrm{~d}$.

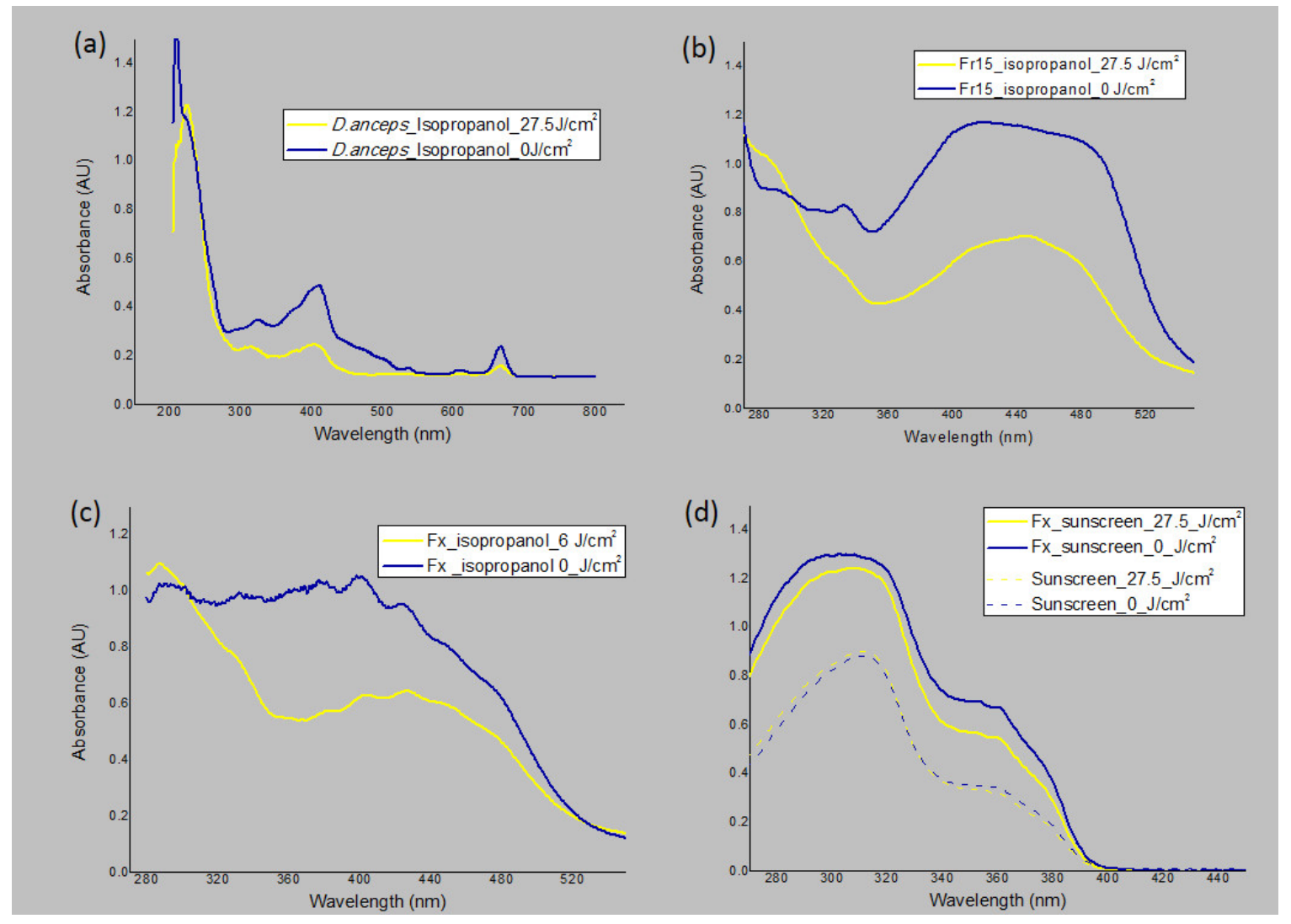

Figure 2. Photostability studies based on the electromagnetic spectrum of the samples irradiated (yellow line) or not (blue line). (a) D. anceps extract in solution irradiated or not with $27.5 \mathrm{~J} / \mathrm{cm}^{2}$. (b) Fr15 fraction containing fucoxanthin in solution irradiated or not with $27.5 \mathrm{~J} / \mathrm{cm}^{2}$. (c) Fucoxanthin (Fx) in solution irradiated or not with $6 \mathrm{~J} / \mathrm{cm}^{2}$. (d) Fx in a sunscreen formulation vs. sunscreen alone (dashed line) irradiated or not with $27.5 \mathrm{~J} / \mathrm{cm}^{2} ; n=3$, three independent experiments. 
Table 2. Reduction of absorbance after irradiation with different doses of UVA light expressed in percentage. Calculation considering the Area under the Curve (AUC) between samples irradiated or not in triplicates.

\begin{tabular}{ccccc}
\hline \multirow{2}{*}{ Sample } & \multirow{2}{*}{ Irradiation Dose $\left(\mathbf{J} / \mathbf{c m}^{2}\right)$} & \multicolumn{3}{c}{ Mean of the Reduction of Absorbance after Irradiation (\%) } \\
\cline { 3 - 5 } & & UVB & UVA & VIS \\
\hline Crude Extract & 27.5 & 28.5 & 43.2 & 33.7 \\
Fraction F15 & 27.5 & 4.0 & 44.0 & 49.0 \\
Fucoxanthin Isolated & $6^{* *}$ & 0.0 & 35.0 & 21.0 \\
Fucoxanthin in Sunscreen & 27.5 & 5.8 & 16.5 & NE \\
\hline
\end{tabular}

${ }^{*}$ Fucoxanthin rich fraction, ${ }^{* *}$ dose defined as enough to induce phototoxic responses, NE: Non-evaluated (sunscreen with absence of absorbance in the VIS range).

\subsection{Phototoxicity in the Monolayer and RHS Assays}

The prediction model classified the positive control (norfloxacin) as phototoxic and within the MPE range that was recommended by the OECD Test Guideline 432 (0.340 to 0.900) [26]. The crude extract was considered cytotoxic (IC50-UV $2.7 \mu \mathrm{g} / \mathrm{mL}$ ), and its phototoxicity could not be assessed since it compromised all the cells when evaluated in the concentration range of 6.4 to $100 \mathrm{~g} / \mathrm{mL}$ (Table 3). Fraction F15a containing fucoxanthin was considered less cytotoxic than the crude extract $\left(\mathrm{IC}_{50}-\mathrm{UV}\right.$ 26.12 and $25.22 \mu \mathrm{g} / \mathrm{mL}$ ) but was deemed to be phototoxic (MPE: 0.343 and 0.478 ). Fucoxanthin only showed phototoxic potential (MPE: 0.920 and 0.915 ) and no cytotoxic potential ( $\mathrm{IC}_{50}$ not determined in the range of 6.4 to $100 \mu \mathrm{g} / \mathrm{mL}$ ) to fibroblasts 3T3 (Table 3).

Table 3. Data from the $3 \mathrm{~T} 3$ fibroblasts phototoxicity assay of the promising alga fractions, pure fucoxanthin, and the positive control (norfloxacin).

\begin{tabular}{cccccc}
\hline Chemical & IC $_{\mathbf{5 0}}-\mathbf{U V}$ & IC $_{\mathbf{5 0}}+\mathbf{U V}$ & MPE & PIF & Result \\
\hline Extract & 2.76 & 3.05 & -0.014 & 0.90 & cytotoxic \\
Fraction F15a & 26.12 & 4.45 & 0.343 & 7.08 & photo/cytotoxic \\
& 25.22 & 2.59 & 0.478 & 16.13 & photo/cytotoxic \\
Fucoxanthin & - & 2.77 & 0.920 & 48.21 & phototoxic \\
Positive Control (Norfloxacin) & - & 5.91 & 0.915 & 17.04 & phototoxic \\
\hline
\end{tabular}

$n=1$ or 2 independent experiments, -: values not determined in the studied concentration range

Regarding the phototoxic potential of fucoxanthin, its molecular weight is high, $658.90 \mathrm{~g} / \mathrm{mol}$, which indicated that this substance would have a reduced bioavailability through the stratum corneum and stratified keratinocytes layers of the skin, which could lead to the absence of phototoxicity in vivo when topically applied. To confirm this hypothesis, we evaluated fucoxanthin for the phototoxicity potential in the RHS model, at $0.5 \%(w / v)$, which is within the concentration range that is usually employed for antioxidants in a cosmetic formulation $(0.01 \%-1 \%)$.

RHE and RHS, due to the presence of a stratum corneum, appear to be capable of detecting known human dermal phototoxicants. Consequently, under adequate test conditions, a negative result in a 3D skin model indicates that the acute photoirritation potential of the formulation can be regarded as low. In this case, negative test results do not generally preclude further clinical photosafety assessment while using the to-be-marketed formulation [29].

The positive phototoxic control 3\% ketoprofen was correctly classified, since it showed a reduction of approximately $41 \%$ in cell viability when compared to the non-irradiated tissue, which is higher than the cut off value of $30 \%$ reduction that was determined for the assay (Figure 3). In contrast, fucoxanthin reduced less than $30 \%$ in cell viability and showed $8.7 \%$ difference between the irradiated and non-irradiated RHS models, proving to be non-phototoxic at this concentration onto RHS. 


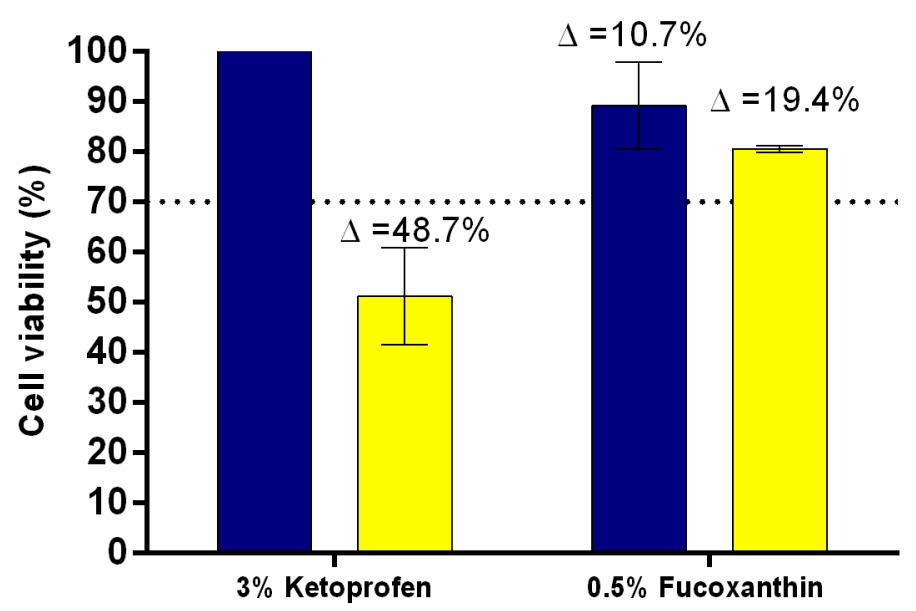

Figure 3. Phototoxicity assay using in-house Reconstructed human skin (RHS)-MTT assay, the positive control 3\% ketoprofen was phototoxic ( $\Delta>$ cut-off $30 \%$ ) and $0.5 \%$ fucoxanthin was non-phototoxic (cell viability $\sim 99 \%$ ) when irradiated (yellow bar) or not (blue bar), mean $\pm \mathrm{SD}, n=2$ in two independent experiments.

\subsection{HaCat Antioxidant Activity by Detection of Intracellular ROS using $\mathrm{DCFH}_{2}-\mathrm{DA}$}

After the non-phototoxic response that was observed in the RHS, the protective effect of fucoxanthin was evaluated by the detection of intracellular ROS immediately after UVA radiation using a probe $2^{\prime}, 7^{\prime}$-DCFH $\mathrm{H}_{2}$-DA in keratinocytes HaCat. The dose of $4 \mathrm{~J} / \mathrm{cm}^{2}$ used was defined by many authors, including Chignell and Sik [38], after no significant difference in viability was observed between control cells and cells exposed to this dose higher than $20 \%$, while an increase in the DCF photochemical reactions (ROS formation) was observed [38]. Cellular esterases hydrolyze the probe that is cell-permeable to the non-fluorescent DCFH derivative [39]. In the presence of hydrogen peroxide, hydroxyl radicals, carbonate, and nitrite, DCFH is oxidized to the highly fluorescent DCF, which can be monitored by several fluorescence-based techniques derivative $[39,40]$. The results demonstrated that UVA radiation-induced ROS generation in the keratinocyte cell line $(100 \%)$ when compared to the untreated control non-irradiated. The positive control norfloxacin $(100 \mu \mathrm{g} / \mathrm{mL})$ induced an increase of ROS production of around $25 \%$ in comparison to the untreated irradiated control (Figure 4). On the other hand, the antioxidant quercetin $(10 \mu \mathrm{g} / \mathrm{mL})$ induced a reduction of ROS generation of around $46 \%$ after UVA irradiation (Figure 4). The treatment with fucoxanthin at 1, 10, and $100 \mu \mathrm{g} / \mathrm{mL}$ induced a significant reduction of ROS production of about $17 \%, 15 \%$, and $65 \%$, respectively, when compared to the untreated irradiated control $(p<0.001)$ (Figure 4$)$. However, this effect was not observed for fucoxanthin $0.1 \mu \mathrm{g} / \mathrm{mL}$, a dose that provided a reduction of $12 \%$, which was not considered statistically significant when compared to the control $(p>0.05)$. Furthermore, treatment with fucoxanthin at $100 \mu \mathrm{g} / \mathrm{mL}$ induced the maximal reduction of ROS production, which was statistically different from the other studied concentrations $(0.1,1$, and $10 \mu \mathrm{g} / \mathrm{mL})(p<0.001)$. 


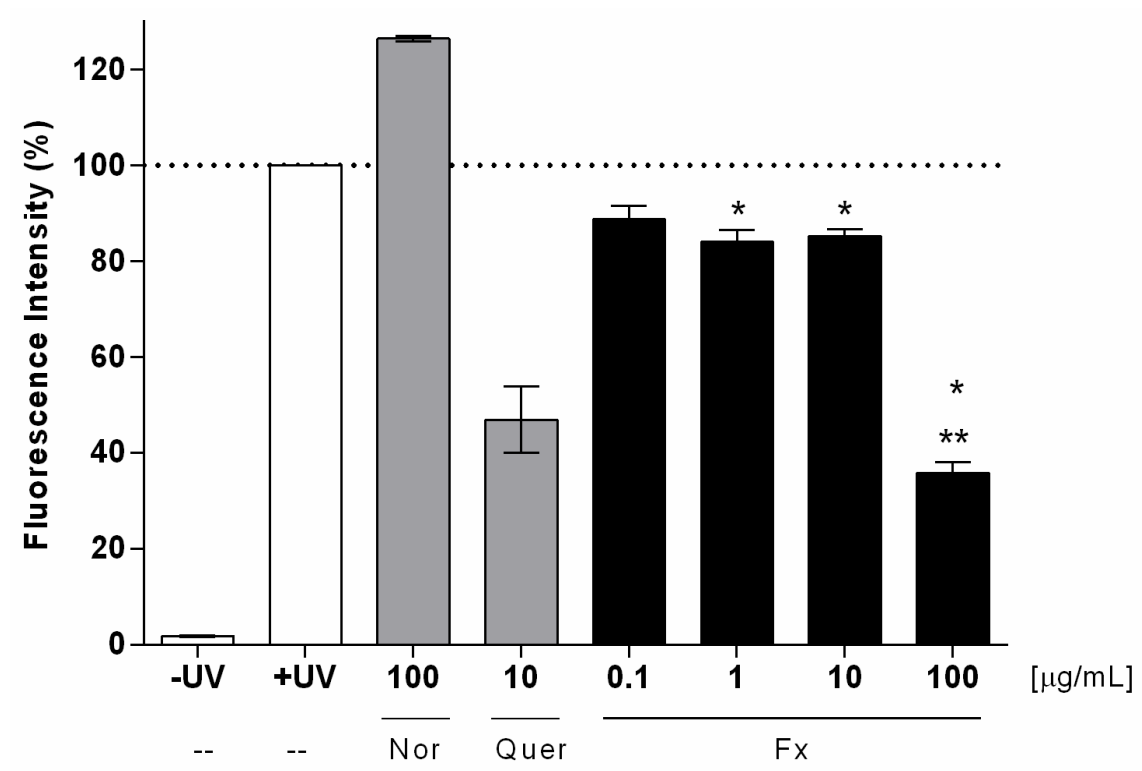

Figure 4. Intracellular Reactive Oxygen Species generation in HaCat after UVA irradiation $\left(4 \mathrm{~J} / \mathrm{cm}^{2}\right)$ using a fluorescent probe DCFH2-DA; untreated irradiated (+UV) and non-irradiated (-UV); norfloxacin-Nor (control); quercetin-Quer (control); fucoxanthin-Fx. Where "*" means significantly different from untreated control irradiated (+UV) $(p<0.001)$ and "*** significantly different from fucoxanthin at $0.1,1$, and $10 \mu \mathrm{g} / \mathrm{mL}(p<0.001)$. Mean $\pm \mathrm{SD}, n=3$ in three independent experiments.

\subsection{RHS Antioxidant Activity by Detection of Intracellular ROS Using $\mathrm{DCFH}_{2}-\mathrm{DA}$}

Following the same mechanism of the probe $\mathrm{DCFH}_{2}-\mathrm{DA}$, but this time with a sunscreen containing or not $0.5 \%$ of fucoxanthin applied in RHS tissues $[33,34]$, the results demonstrated that the UVA radiation increased ROS generation in the untreated RHS control irradiated when compared to the untreated and not irradiated control $(p>0.05)$, (Figures 5 and $6 a, b)$. On the other hand, the sunscreen containing fucoxanthin $0.5 \%(w / v)$ induced a significant reduction of ROS generation after UVA irradiation when compared to the untreated control irradiated (+UV) and when compared to the sunscreen without fucoxanthin (Figures 5 and 6a,d). RHS models only treated with sunscreen induced similar ROS production than untreated control irradiated (+UV) $(p>0.05)$ (Figures 5 and $6 c, d)$.

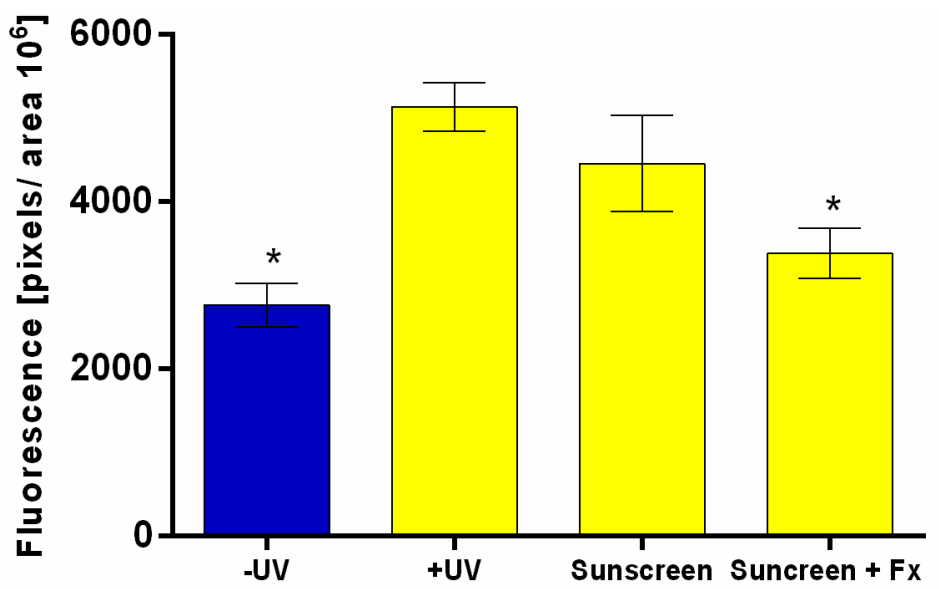

Figure 5. Reconstructed human skin after UVA irradiation $\left(10 \mathrm{~J} / \mathrm{cm}^{2}\right)$ using a fluorescent probe $\mathrm{DCFH}_{2}$-DA. Reactive Oxygen Species generation quantified by the fluorescent intensity in pixels/area. Untreated (blue bar non-irradiated and yellow bars irradiated); sunscreen and sunscreen plus $0.5 \%$ fucoxanthin (Fx). Where "*" means significantly different from untreated irradiated (+UV) and from sunscreen treated models $(p<0.001)$. Mean $\pm \mathrm{SD}, n=3$ in three independent experiments. 
(a)

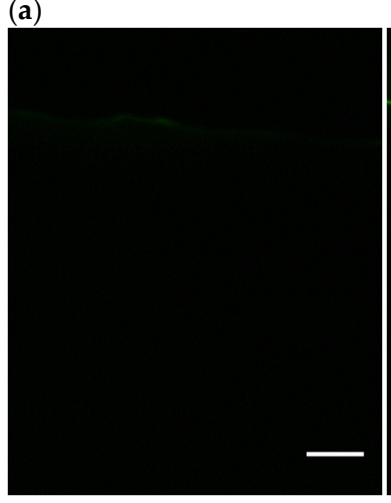

(b)

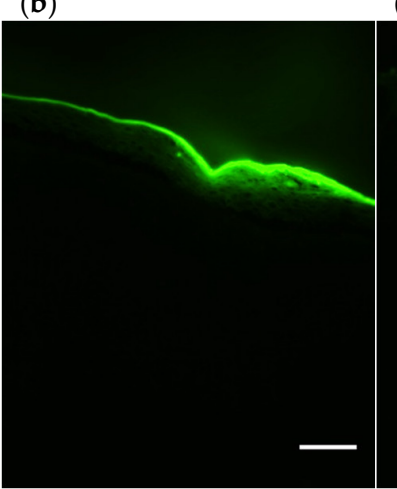

(c)

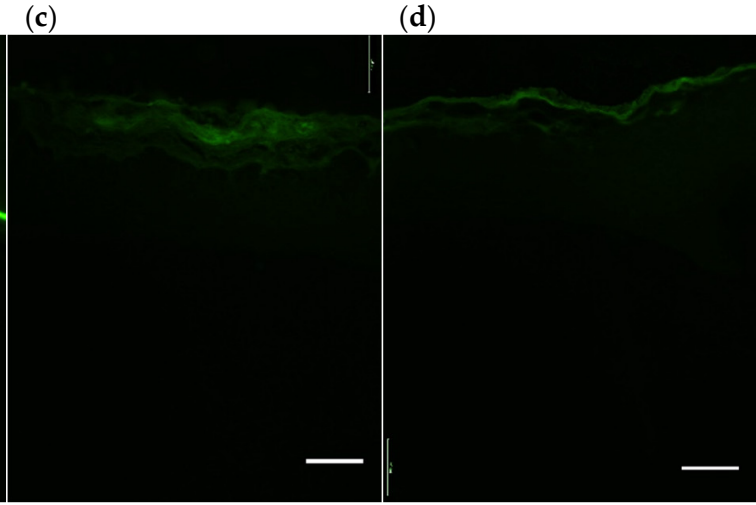

Figure 6. Representative reconstructed human skin (RHS) sessions $(10 \mu \mathrm{m})$ exposed to a fluorescent probe $\mathrm{DCFH}_{2}$-DA and submitted or not to UVA irradiation $\left(10 \mathrm{~J} / \mathrm{cm}^{2}\right)$ - (a) untreated non-irradiated; (b) untreated irradiated; (c) sunscreen irradiated; and, (d) sunscreen plus $0.5 \%$ fucoxanthin irradiated. Green fluorescent intensity represents the Reactive Oxygen Species (ROS) generation in the tissues. Scale bars $=100 \mu \mathrm{m}, n=3$; three independent experiments.

\section{Discussion}

The marine carotenoid fucoxanthin that was isolated in this study from the alga D. anceps was the main carotenoid present in this brown alga [41]. It absorbs in the UV/VIS region, which is interesting for photoprotection and presents promising antioxidant properties that are observed in mice reported in the literature [12]. In the present study, fucoxanthin was, for the first time, evaluated in vitro by the toxicological and photoprotective perspective of its use in the human skin using 3D RHS.

Fucoxanthin showed photoinstability when being evaluated in an organic solvent. However, UV filters or boosters should be stable under UV exposure, since their exposure to sunlight might lead to photodegradation reactions that can compromise their physical properties and lead to the formation of undesirable photoproducts [42]. Zhang and Tang [43] discussed that the instability of carotenes is related to the poly chain conjugate and its susceptibility to oxidation, isomerization by heat, light, and chemical interactions. After analyzing the chemical UVA/VIS photoinstability of fucoxanthin, with degradation being over the acceptable range of $20 \%$ after a $6 \mathrm{~J} / \mathrm{cm}^{2} \mathrm{UVA}$ dose, we added fucoxanthin at $0.5 \%$ to a sunscreen formulation to assess photostability at a $27.5 \mathrm{~J} / \mathrm{cm}^{2} \mathrm{UVA}$ dose. In this study, the sunscreen formulation that contains a combination of two UV filters considered to be photo unstable (avobenzone and ethylhexyl methoxycinnamate) was studied in order to assess the fucoxanthin capabilities of alteration in the photostability of this photo unstable combination. However, the sunscreen plus fucoxanthin showed acceptable photodegradation (Figure 2d). Surprisingly, besides that, we observed that the sunscreen plus fucoxanthin enhanced UVA and UVB absorption by $72 \%$, showing in vitro booster properties of fucoxanthin that should be further investigated.

According to ICH [44], the intrinsic photostability of a substance or product shall be demonstrated in such a way that exposure to light does not result in unacceptable changes [44].

Addressing the tiered strategy to assess acute phototoxicity according to ICH recommendations [18], 3T3 NRU-PT is the first step of the biological assays and it is considered to be a standalone test for negative results due to its high sensitivity $(100 \%)$ for the identification of absence of phototoxic potential [45]. When a positive result is obtained, i.e. fucoxanthin showed a phototoxic potential (MPE: 0.917), a follow-up testing should be performed to obtain data with models that better reflect the human situation, such as 3D skin models [45], since the 3T3 NRU-PT test is overestimated and it can produce false-positive results due to the lack of stratum corneum [28]. Firstly, our 3D full-thickness skin model proved to be able to detect the phototoxic potential of positive control, reducing the viability by more than $30 \%$ [28]. Secondly, fucoxanthin at $0.5 \%$ did not present phototoxicity (Figure 4 ). Therefore, the combined phototoxicity assays (monolayer and RHS) suggest that fucoxanthin would not be phototoxic to the human skin at $0.5 \%$ due to the reduced bioavailability through the stratum corneum and in the stratified epidermis. It is important to 
mention that skin models are more permeable than human skin [46], which means that they hardly produce false-negative results, which is very important when predicting the toxic potential of unknown substances. In addition, the viable epidermis is made of keratinocytes, which are less sensitive than fibroblasts to xenobiotics and UV radiation.

In the efficacy assay on monolayers, fucoxanthin not only did not harm the HaCat keratinocytes, but also protected the cells from UVA-induced ROS formation in a concentration-dependent manner (maximal effect at $0.01 \%$ ) (Figure 4 ). The reduction in ROS production was probably due to its antioxidant properties under anoxic conditions, well described by other studies using in chemico (DPPH; ABTS) [14] and in vitro methods (HepG2, HaCat, PC12) [47]. While the other carotenoids have virtually no scavenging ability against ROS, fucoxanthin donates electrons as a part of its mechanism of capturing free radicals [12]. Furthermore, we also observed a significant reduction in the ROS production in RHS (complex 3D tissue) treated and irradiated with sunscreen plus fucoxanthin that we did not observe in the RHS that was treated with sunscreen alone (Figures 5 and 6). This suggests that fucoxanthin can also protect viable epidermis against UVA-induced ROS production, which is in agreement with the fucoxanthin protection observed in HaCat keratinocytes. These results could be considered to be very positive for the risk-benefit of its dermatological use, since fucoxanthin that reaches viable epidermis protects against UVA-induced ROS production (Figure 6d).

Our study corroborates those reported before [48], which employed the HaCat cell line and hairless mice to study the UVB protective effects of commercial all-trans-fucoxanthin (Sigma). They observed that fucoxanthin has anti-inflammatory activity by downregulating Cyclooxygenase- 2 (COX-2) expression after UVB irradiation (mice) and a photoprotective effect against oxidative stress that is caused by UVB exposure via an increase of nuclear factor E2-related factor 2 (Nrf2) expression. Thus, although Rodríguez-Luna et al. [48] obtained valuable information from hairless mice, it is well known that human adverse events cannot always be detected in animals, due to inherent genetic and physiological differences between species and that skin model constructed with human cells and physiologic relevant microarchitecture contributes to the better prediction of human effects. In the previous study of our group, commercial fucoxanthin at the same concentration, presented an absence of irritation, absence of morphological changes in the histology, and no significant dysregulation on homeostasis, metabolism, and in the inflammatory genes studied after following the OECD protocol for skin irritation [49].

Finally, it is important to mention that another well-known molecule, $\beta$-Carotene, a vitamin A precursor, is a popular "secondary" UV filter (characterized by a sun protection factor lower than 2), has a controversial use in the literature, regarding its antioxidant/prooxidant effect, depending on its concentration and $\mathrm{O}_{2}$ tension [2,22,50-52]. However, $\beta$-Carotene is able to protect the collagen structure from infrared light in the skin [53] and it is used in cosmetic formulations for aged skin and actinic keratosis [51], which, for instance, could also suggest some skin benefits from the topical use of fucoxanthin when tested in vivo, due to the similarities of their molecular structures. In addition, fucoxanthin when orally administered in mice is reported to have low accumulation in the skin [54], which underscores the interest of topical use of fucoxanthin and such confirmation of its safety and effectiveness suggested by the present study.

\section{Conclusions}

In conclusion, we developed an effective extraction and purification of all-trans-fucoxanthin from the brown alga $D$. anceps. Although fucoxanthin presented chemical UV photo-instability, it increased by $72 \%$ of the total sunscreen UV absorption spectra (UVA and UVB) when added to sunscreen at $0.5 \%$, presenting UV-booster properties with an acceptable photostability. The beneficial use of topical fucoxanthin should be further investigated in vivo in the concentration range of $0.01-0.5 \%(w / v)$. As, in this range, we observed an absence of phototoxicity in the RHS model and protective potential against UVA-induced ROS formation both in HaCat monolayers and on RHS models, which might contribute to improving the photoprotective potential of sunscreens. 
Supplementary Materials: The following are available online at http://www.mdpi.com/2076-3921/9/4/328/s1, Figure S1: Chromatogram of the elution semi-preparative scale-carotenoid isolation, Figure S2: Chromatogram of the semi-preparative scale subfraction, analyzed in $450 \mathrm{~nm}$-absorption region of fucoxanthin at a higher intensity (Au 450), Retention Time (RT) = 5.75 min black line, $650 \mathrm{~nm}$-region of the band's absorption of chlorophyll "a" lower intensity. RT $\sim 3 \mathrm{~min}$, pink line, Figure S3: Chromatogram of the elution of the subfraction analytical scale, analyzed in (a) the $450 \mathrm{~nm}$-absorption region of fucoxanthin at a higher intensity ( $3 \mathrm{Au})$, Retention time (RT) = $3.5 \mathrm{~min}$; (b) $650 \mathrm{~nm}$ - the area of the chlorophyll absorption bands at a lower intensity (0.025 Au), RT $\sim 6.5 \mathrm{~min}$.

Author Contributions: Conceptualization, R.S.N.T., L.R.G., H.M.D.; investigation, R.S.N.T., C.M.K., K.d.C.P. and G.T.d.A.; methodology, R.S.N.T., C.M.K., C.G.B., S.S.M.-E., H.M.D.; writing-original draft preparation, R.S.N.T., and L.R.G.; writing-review and editing, R.S.N.T., P.C.; H.M.D. and L.R.G.; visualization, R.S.N.T. and L.R.G. supervision, L.R.G. and H.M.D.; project administration, L.R.G. and H.M.D.; funding acquisition, R.S.N.T., P.C., H.M.D., and L.R.G. All authors have read and agreed to the published version of the manuscript.

Funding: This research was funded by call N 64/2013, MCTI/CNPq/FNDCT-Ação Transversal-Programa Antártico Brasileiro-PROANTAR, from the Brazilian Government, R.S.N.T. gratefully acknowledges a doctoral scholarship from CNPq (grant number 132062/2014-3).

Acknowledgments: We are thankful to Ribeirão Preto State Hospital and to the Maria de Fátima Galli Sorita, Ana Laura Ferreira Marsico Dalto, and Alexandra Longo Camperoni for the partnership providing the foreskin. The authors are also grateful to Nair Sumie Yokoya and Aline Paternostro Martins for the identification, collection and depositing the voucher specimens in the herbarium of Botanical Institute of São Paulo. We thank Norberto Peporine Lopes for the MS-ESI analyses performed in the Department of Chemistry, Faculty of Philosophy, Sciences, and Languages of Ribeirão Preto and the Department of Physics and Chemistry, Faculty of Pharmaceutical Sciences of Ribeirão Preto-USP.

Conflicts of Interest: The authors declare no conflict of interest. The funders had no role in the design of the study; in the collection, analyses, or interpretation of data; in the writing of the manuscript, or in the decision to publish the results.

\section{References}

1. Fourtanier, A.; Moyal, D.; Seite, S. UVA filters in sun-protection products: Regulatory and biological aspects. Photochem. Photobiol. Sci. 2012, 11, 81-89. [CrossRef] [PubMed]

2. Freitas, J.V.; Gaspar, L.R. In vitro photosafety and efficacy screening of apigenin, chrysin and beta-carotene for UVA and VIS protection. Eur. J. Pharm. Sci. 2016, 89, 146-153. [CrossRef]

3. Liebel, F.; Kaur, S.; Ruvolo, E.; Kollias, N.; Southall, M.D. Irradiation of skin with visible light induces reactive oxygen species and matrix-degrading enzymes. J. Investig. Dermatol. 2012, 132, 1901-1907. [CrossRef] [PubMed]

4. Damiani, E.; Baschong, W.; Greci, L. UV-Filter combinations under UV-A exposure: Concomitant quantification of over-all spectral stability and molecular integrity. J. Photochem. Photobiol. B 2007, 87, 95-104. [CrossRef] [PubMed]

5. Gaspar, L.R.; Tharmann, J.; Maia Campos, P.M.; Liebsch, M. Skin phototoxicity of cosmetic formulations containing photounstable and photostable UV-filters and vitamin A palmitate. Toxicol. Vitr. 2013, 27, 418-425. [CrossRef]

6. Matsumoto, H.; Adachi, S.; Suzuki, Y. Estrogenic activity of ultraviolet absorbers and the related compounds. Yakugaku Zasshi 2005, 125, 643-652. [CrossRef] [PubMed]

7. Ozáez, I.; Martínez-Guitarte, J.L.; Morcillo, G. Effects of in vivo exposure to UV filters (4-MBC, OMC, BP-3, 4-HB, OC, OD-PABA) on endocrine signaling genes in the insect Chironomus riparius. Sci. Total. Environ. 2013, 456-457, 120-126. [CrossRef] [PubMed]

8. Tovar-Sánchez, A.; Sánchez-Quiles, D.; Basterretxea, G.; Benedé, J.L.; Chisvert, A.; Salvador, A.; Moreno-Garrido, I.; Blasco, J. Sunscreen products as emerging pollutants to coastal waters. PLoS ONE 2013, 8, e65451. [CrossRef]

9. Downs, C.A.; Kramarsky-Winter, E.; Segal, R.; Fauth, J.; Knutson, S.; Bronstein, O.; Ciner, F.R.; Jeger, R.; Lichtenfeld, Y.; Woodley, C.M.; et al. Toxicopathological Effects of the Sunscreen UV Filter, Oxybenzone (Benzophenone-3), on Coral Planulae and Cultured Primary Cells and Its Environmental Contamination in Hawaii and the U.S. Virgin Islands. Arch. Environ. Contam. Toxicol. 2016, 70, 265-288. [CrossRef]

10. Pandika, M. Looking to Nature for New Sunscreens. ACS Cent. Sci. 2018, 4, 788-790. [CrossRef]

11. Sohn, M. UV Booster and Photoprotection. In Principles and Practice of Photoprotection; Wang, S.Q., Lim, H.W., Eds.; Springer International Publishing: Cham, Switzerland, 2016; pp. 227-245.

12. D'Orazio, N.; Gemello, E.; Gammone, M.A.; de Girolamo, M.; Ficoneri, C.; Riccioni, G. Fucoxantin: A treasure from the sea. Mar. Drugs 2012, 10, 604-616. [CrossRef] [PubMed] 
13. Riccioni, G.; D’Orazio, N.; Franceschelli, S.; Speranza, L. Marine carotenoids and cardiovascular risk markers. Mar. Drugs 2011, 9, 1166-1175. [CrossRef] [PubMed]

14. Xia, S.; Wang, K.; Wan, L.; Li, A.; Hu, Q.; Zhang, C. Production, characterization, and antioxidant activity of fucoxanthin from the marine diatom Odontella aurita. Mar. Drugs 2013, 11, 2667-2681. [CrossRef] [PubMed]

15. Urikura, I.; Sugawara, T.; Hirata, T. Protective effect of Fucoxanthin against UVB-induced skin photoaging in hairless mice. Biosci. Biotechnol. Biochem. 2011, 75, 757-760. [CrossRef] [PubMed]

16. Mathes, S.H.; Ruffner, H.; Graf-Hausner, U. The use of skin models in drug development. Adv. Drug Deliv. Rev. 2014, 69-70, 81-102. [CrossRef]

17. Ceridono, M.; Tellner, P.; Bauer, D.; Barroso, J.; Alépée, N.; Corvi, R.; De Smedt, A.; Fellows, M.D.; Gibbs, N.K.; Heisler, E.; et al. The 3T3 neutral red uptake phototoxicity test: Practical experience and implications for phototoxicity testing-the report of an ECVAM-EFPIA workshop. Regul. Toxicol. Pharmacol. 2012, 63, 480-488. [CrossRef]

18. ICH. Photosafety Evaluation of Pharmaceuticals. In S10 Guideline; ICH: Geneva, Switzerland, 2013.

19. Catarino, C.M.; do Nascimento Pedrosa, T.; Pennacchi, P.C.; de Assis, S.R.; Gimenes, F.; Consolaro, M.E.L.; de Moraes Barros, S.B.; Maria-Engler, S.S. Skin corrosion test: A comparison between reconstructed human epidermis and full thickness skin models. Eur. J. Pharm. Biopharm. 2018, 125, 51-57. [CrossRef]

20. Cambon, M.; Issachar, N.; Castelli, D.; Robert, C. An in vivo method to assess the photostability of UV filters in a sunscreen. J. Cosmet. Sci. 2001, 52,1-11.

21. Whitehead, K.; Hedges, J.I. Photodegradation and photosensitization of mycosporine-like amino acids. J. Photochem. Photobiol. B 2005, 80, 115-121. [CrossRef]

22. Freitas, J.V.; Lopes, N.P.; Gaspar, L.R. Photostability evaluation of five UV-filters, trans-resveratrol and beta-carotene in sunscreens. Eur. J. Pharm. Sci. 2015, 78, 79-89. [CrossRef]

23. Maia-Campos, P.M.B.G.; Benevenuto, C.G.; Calixto, L.S.; Melo, M.O.; Pereira, K.C.; Gaspar, L.R. Palmariapalmata, Cichorium intybus, and Medicago sativa extracts in cosmetic formulations: An integrated approach of in vitro toxicity and in vivo acceptability studies. Cutan. Ocul. Toxicol. 2019, 38, 322-329. [CrossRef] [PubMed]

24. Diffey, B.L. Optimizing the spectral absorption profile of sunscreens. Int. J. Cosmet. Sci. 2017, 39, 90-92. [CrossRef]

25. Liebsch, M.; Spielmann, H.; Pape, W.; Krul, C.; Deguercy, A.; Eskes, C. UV-induced effects. Altern. Lab. Anim. 2005, 33 (Suppl. S1), 131-146. [CrossRef] [PubMed]

26. OECD. Test No. 432: In vitro 3T3 NRU Phototoxicity Test, OECD Guidelines for the Testing of Chemicals; OECD Publishing: Paris, France, 2019.

27. Pennacchi, P.C.; de Almeida, M.E.; Gomes, O.L.; Faião-Flores, F.; de Araújo Crepaldi, M.C.; Dos Santos, M.F.; de Moraes Barros, S.B.; Maria-Engler, S.S. Glycated Reconstructed Human Skin as a Platform to Study the Pathogenesis of Skin Aging. Tissue Eng. Part A 2015, 21, 2417-2425. [CrossRef] [PubMed]

28. Kandarova, H.; Liebsch, M. The EpiDermTM Phototoxicity Test (EpiDermTM H3D-PT) In Alternatives for Dermal Toxicity Testing; Springer International Publishing: Cham, Switzerland, 2017.

29. Liebsch, M.; Traue, D.; Barrabas, C.; Spielmann, H.; Gerberick, G.F.; Cruse, L.; Diembeck, W.; Pfannenbecker, U.; Spieker, J.; Holzhutter, H.-G.; et al. Prevalidation of the epiderm ${ }^{\mathrm{TM}}$ phototoxicity test. In Proceedings of International Scientific Conference, Alternatives to Animal Testing, 2nd ed.; CPL Press: Brussels, Belgium, 1999; pp. 160-166.

30. OECD. Test No. 439: In Vitro Skin Irritation: Reconstructed Human Epidermis Test Method; OECD Publishing: Paris, France, 2019.

31. Pygmalion, M.J.; Ruiz, L.; Popovic, E.; Gizard, J.; Portes, P.; Marat, X.; Lucet-Levannier, K.; Muller, B.; Galey, J.B. Skin cell protection against UVA by Sideroxyl, a new antioxidant complementary to sunscreens. Free Radic. Biol. Med. 2010, 49, 1629-1637. [CrossRef] [PubMed]

32. Alves, G.A.D.; Oliveira de Souza, R.; Ghislain Rogez, H.L.; Masaki, H.; Fonseca, M.J.V. Cecropia obtusa extract and chlorogenic acid exhibit anti aging effect in human fibroblasts and keratinocytes cells exposed to UV radiation. PLoS ONE 2019, 14, e0216501. [CrossRef]

33. Marionnet, C.; Pierrard, C.; Golebiewski, C.; Bernerd, F. Diversity of biological effects induced by longwave UVA rays (UVA1) in reconstructed skin. PLoS ONE 2014, 9, e105263. [CrossRef]

34. Rasmussen, C.; Gratz, K.; Liebel, F.; Southall, M.; Garay, M.; Bhattacharyya, S.; Simon, N.; Vander Zanden, M.; Van Winkle, K.; Pirnstill, J.; et al. The StrataTest ${ }^{\circledR}$ human skin model, a consistent in vitro alternative for toxicological testing. Toxicol. Vitr. 2010, 24, 2021-2029. [CrossRef] 
35. Kuczynska, P.; Jemiola-Rzeminska, M.; Strzalka, K. Photosynthetic Pigments in Diatoms. Mar. Drugs 2015, 13, 5847-5881. [CrossRef]

36. Mori, K.; Ooi, T.; Hiraoka, M.; Oka, N.; Hamada, H.; Tamura, M.; Kusumi, T. Fucoxanthin and Its Metabolites in Edible Brown Algae Cultivated in Deep Seawater. Mar. Drugs 2004, 2, 63-72. [CrossRef]

37. Hojerová, J.; Medovcíková, A.; Mikula, M. Photoprotective efficacy and photostability of fifteen sunscreen products having the same label SPF subjected to natural sunlight. Int. J. Pharm. 2011, 408, 27-38. [CrossRef] [PubMed]

38. Chignell, C.F.; Sik, R.H. A photochemical study of cells loaded with $2^{\prime}, 7^{\prime}$-dichlorofluorescin: Implications for the detection of reactive oxygen species generated during UVA irradiation. Free Radic. Biol. Med. 2003, 34, 1029-1034. [CrossRef] [PubMed]

39. Kalyanaraman, B.; Darley-Usmar, V.; Davies, K.J.; Dennery, P.A.; Forman, H.J.; Grisham, M.B.; Mann, G.E.; Moore, K.; Roberts, L.J.; Ischiropoulos, H. Measuring reactive oxygen and nitrogen species with fluorescent probes: Challenges and limitations. Free Radic. Biol. Med. 2012, 52, 1-6. [CrossRef] [PubMed]

40. Wardman, P. Fluorescent and luminescent probes for measurement of oxidative and nitrosative species in cells and tissues: Progress, pitfalls, and prospects. Free Radic. Biol. Med. 2007, 43, 995-1022. [CrossRef] [PubMed]

41. Rautenberger, R.W.C.; Bischof, K. Acclimation to UV radiation and antioxidative defence in the endemic Antarctic brown macroalga Desmarestia anceps along a depth gradient. Polar Biol. 2013, 36, 1779-1789. [CrossRef]

42. Santos, A.J.; Miranda, M.S.; Esteves da Silva, J.C. The degradation products of UV filters in aqueous and chlorinated aqueous solutions. Water Res. 2012, 46, 3167-3176. [CrossRef]

43. Zhang, H.; Tang, Y.; Zhang, Y.; Zhang, S.; Qu, J.; Wang, X.; Kong, R.; Han, C.; Liu, Z. Fucoxanthin: A Promising Medicinal and Nutritional Ingredient. Evid. Based Complement. Altern. Med. 2015, 2015, 723515. [CrossRef]

44. ICH. Photostability Testing of New Drug Substances and Products. In Q1B Guideline; ICH: Geneva, Switzerland, 1996.

45. Gaspar, L.R.; Kawakami, C.M.; Benevenuto, C.G. Overview on the Current Status of Available Test Methods and Additional Promising Methods for Assessing UV-Induced Effects. In Alternatives for Dermal Toxicity Testing; (CSpringer International Publishing AG: Cham, Switzerland, 2017; p. 463.

46. Kejlová, K.; Jírová, D.; Bendová, H.; Kandárová, H.; Weidenhoffer, Z.; Kolárová, H.; Liebsch, M. Phototoxicity of bergamot oil assessed by in vitro techniques in combination with human patch tests. Toxicol. Vitr. 2007, 21, 1298-1303. [CrossRef]

47. Zeng, J.; Zhang, Y.; Ruan, J.; Yang, Z.; Wang, C.; Hong, Z.; Zuo, Z. Protective effects of fucoxanthin and fucoxanthinol against tributyltin-induced oxidative stress in HepG2 cells. Environ. Sci. Pollut. Res. Int. 2018, 25, 5582-5589. [CrossRef]

48. Rodríguez-Luna, A.; Ávila-Román, J.; González-Rodríguez, M.L.; Cózar, M.J.; Rabasco, A.M.; Motilva, V.; Talero, E. Fucoxanthin-Containing Cream Prevents Epidermal Hyperplasia and UVB-Induced Skin Erythema in Mice. Mar. Drugs 2018, 16, 378. [CrossRef]

49. Tavares, R.S.N.; Maria-Engler, S.S.; Colepicolo, P.; Debonsi, H.M.; Schäfer-Korting, M.; Marx, U.; Gaspar, L.R.; Zoschke, C. Skin Irritation Testing beyond Tissue Viability: Fucoxanthin Effects on Inflammation, Homeostasis, and Metabolism. Pharmaceutics 2020, 12, 136. [CrossRef] [PubMed]

50. Biesalski, H.K.; Obermueller-Jevic, U.C. UV light, beta-carotene and human skin-Beneficial and potentially harmful effects. Arch. Biochem. Biophys. 2001, 389, 1-6. [CrossRef] [PubMed]

51. Bayerl, C. Beta-carotene in dermatology: Does it help? Acta Dermatovenerol. APA 2008, 17, 160-162.

52. Zhang, P.; Omaye, S.T. Antioxidant and prooxidant roles for beta-carotene, alpha-tocopherol and ascorbic acid in human lung cells. Toxicol. Vitr. 2001, 15, 13-24. [CrossRef]

53. Fernández, E.; Fajarí, L.; Rodríguez, G.; Cócera, M.; Moner, V.; Barbosa-Barros, L.; Kamma-Lorger, C.S.; de la Maza, A.; López, O. Reducing the Harmful Effects of Infrared Radiation on the Skin Using Bicosomes Incorporating $\beta$-Carotene. Skin Pharmacol. Physiol. 2016, 29, 169-177. [CrossRef] [PubMed]

54. Hashimoto, T.; Ozaki, Y.; Taminato, M.; Das, S.K.; Mizuno, M.; Yoshimura, K.; Maoka, T.; Kanazawa, K. The distribution and accumulation of fucoxanthin and its metabolites after oral administration in mice. Br. J. Nutr. 2009, 102, 242-248. [CrossRef]

(C) 2020 by the authors. Licensee MDPI, Basel, Switzerland. This article is an open access article distributed under the terms and conditions of the Creative Commons Attribution (CC BY) license (http://creativecommons.org/licenses/by/4.0/). 